\title{
INFLUENCE OF APPLE CULTIVAR, TREE PHENOLOGY, AND LEAF QUALITY ON THE DEVELOPMENT AND MORTALITY OF CHORISTONEURA ROSACEANA (LEPIDOPTERA: TORTRICIDAE)
}

\author{
David W. ONSTAD ${ }^{1}$ and W. HARVEY REISSIG \\ Department of Entomology, New York State Agricultural Experiment Station, Cornell University, Geneva, \\ New York, USA 14456 \\ and Christine A. Shoemaker \\ Department of Environmental Engineering, Cornell University, Ithaca, New York, USA
}

\begin{abstract}
Can. Ent. 118: 123-132 (1986)

The obliquebanded leafroller, Choristoneura rosaceana (Harris), is a polyphagous insect that is òccasionally a serious pest of apple trees. To determine how well adapted it is to this host plant, we studied its nutritional ecology by measuring the development and mortality of larvae and pupae reared on different sets of leaves. We investigated the influence of 3 apple cultivars, 2 time periods (June, July-August), and several leaf types, including those with different ages and different branch positions, on these processes. Larvae and pupae developed more rapidly with lower mortality on younger leaves than on older ones. When larvae were fed leaves collected from the same cultivar and branch position at different times during the season, developmental rates were faster and survival rates were higher earlier in the season. Development and survival were similar on leaves of all cultivars.
\end{abstract}

\begin{abstract}
Résumé
La tordeuse à bandes obliques, Choristoneura rosaceana (Harris), est un insecte polyphage qui est occasionnellement très nuisible dans les pommeraies. Afin d'établir jusqu'à quel point il est bien adapté au pommier, on a étudié son écologie nutritionnelle en mesurant le développement et la mortalité des larves et des pupes obtenues avec différents feuillages. On a étudié les effets, sur ces processus, de 3 cultivars du pommier, 2 périodes de l'été (Juin et Juillet-Août) et plusieurs types de feuilles, y compris des feuilles d'âges différents et occupant des positions différentes sur les branches. Les larves et les pupes se sont développées plus rapidement et avec un meilleur taux de survie sur du feuillage jeune plutôt qu'âgé. Lorsque les larves ont été nourries de feuillage cueilli tôt en saison, les vitesses de développement et taux de survie ont été supérieurs à ceux obtenus avec du feuillage cueilli plus tard. Le développement et la survie se sont avérés similaires sur le feuillage des différents cultivars.
\end{abstract}

\section{Introduction}

The obliquebanded leafroller, Choristoneura rosaceana (Harris), is widely distributed in temperate North America. It is a polyphagous insect that exists primarily on plant hosts in the family Rosaceae. Although apple, Malus domestica, is one of these hosts, it was not one of the original primary hosts for this native insect species. In fact, until the last decade the obliquebanded leafroller (OBLR) was not considered an important pest of apple orchards in New York (Chapman et al. 1968; Chapman and Lienk 1971), because larval densities were low and fruit damage was not significant. Now it is considered a pest in commercial orchards. It is not clear whether this change in status was caused by changes in management practices (Reissig 1978) or by an increased awareness by growers of the damage.

OBLR larvae have been found on most apple cultivars, they feed on leaves from May to September, and they are most often observed on branches at the tips of branches (Onstad 1985; Chapman and Lienk 1971). Chapman et al. (1968) observed higher densities of second-generation moths in June compared with the densities of first-generation moths

IPresent address: Illinois Natural History Survey, Section of Economic Entomology, 607 East Peabody Drive, Champaign, Illinois, USA 61820. 
later in the summer. With their "favorable food factor" hypothesis, they postulated that this difference in densities was due to the lack of young succulent foliage available to the OBLR larvae in July and August.

To manage properly a pest species in a variable environment, its nutritional ecology must be understood. Scriber and Slansky (1981) and Raupp and Denno (1983) have reviewed many of the studies concerning the nutritional ecology of larvae and herbivores. Two aspects of nutritional ecology that have significant effects on pest management are the influences of diet on development and mortality.

The purpose of our study is to describe quantitatively the development and mortality of OBLR on apple. We reared larvae on leaves collected from different positions on branches, from different cultivars, and at different times of the year. A previous study measured the development of the immature stages of OBLR at controlled temperatures (Gangavalli and AliNiazee 1985), but an artificial diet was used. Our study is the first to examine simultaneously the effects of leaf type, cultivar, and tree phenology on the development and mortality of a tortricid leafroller.

\section{Materials and Methods}

Three cultivars of apple, Malus domestica, were used: "Red Rome", "McIntosh', and "Rhode Island Greening" (RIG). "McIntosh" is the most abundant cultivar in New York, and RIG is an important variety for the processing industry. We chose "Rome", because its leaf pubescence is different and it tends to bloom later than the other 2 cultivars. Foliage was collected from ca. 36 trees in the Experiment Station's orchard in Geneva. These 28-year-old trees were planted on M-7 rootstock at a spacing of 10.7 by $6.1 \mathrm{~m}$. The trees were sprayed regularly with captan $50 \mathrm{wp}$ early in the season to control apple scab, but they were not treated with miticides or insecticides during the season.

Larvae were reared individually in cylindrical glass vials. Following the method of Scriber (1977), we kept the excised leaves in florists' water tubes. For most vials, the petiole was passed through a notch in a cork stopper and into the water tube. When the leaf and its petiole were too short, we wrapped parafilm (Parafilm M, American Can Co.) around the water tube, which was placed in the opening of the vial. We changed the leaves after 2-5 days, with an average of 3 days; the frequency of leaf replacement depended upon the size of the larvae. We obtained newly hatched larvae from egg masses produced in a laboratory colony. Larvae were transferred to new leaves with a fine brush, and their condition was checked each time the leaves were changed. Pupae were checked every second day. We recorded dates of death, pupation, and adult emergence. The sex of an individual was determined at emergence.

During all of the tests when new leaves were needed, we collected whole branch terminals and transported them back to the insectary or growth chamber in labelled plastic crispers. If we were unable to place the leaves in the vials immediately, the crispers were placed in a cold-storage room for 1-5 $\mathrm{h}$. This method preserved the freshness of the leaves until we were prepared to remove the appropriate leaves for a given treatment. This procedure also prevented us from returning to the same shoot and incorrectly using it at a later date. We always collected the terminals in the morning between 0700 and 1000 hours. For growing shoots, the second leaf was used, because the first leaf sometimes was not fully unfolded. During June, the number of leaves per extension shoot was also recorded. Approximately 10 leaves per terminal existed on 1 June, and a new leaf developed every $50 \mathrm{DD}_{5.25}$ after that $\left(R^{2}=92 \%\right)$. Thus, the sixth leaf from the tip was approximately $300 \mathrm{DD}_{5,25}$ old. This rate of leaf development was similar for all cultivars during June.

Design of Experiments. To evaluate the influence of tree phenology on development and mortality, experiments were performed at 2 times during the season: 1 set in June and 1 set in July-August. At each time period, the experiments were designed to evaluate the 
influence of the 3 cultivars and the effect of leaf type. We compared a variety of leaf types in the experiments. We compared young and old leaves by selecting leaves from the tip (young) and sixth position (old) on the branch. In another comparison, we used growing leaves at the tip and those that were no longer growing at the tip. The growing leaves were less mature than the second group, but the precise difference in ages was not known.

Early-season Experiments. These tests were begun after petal fall on 31 May. One group of larvae was reared on young leaves (second leaf from tip) and another group was reared on old leaves (sixth leaf from tip). The leaves were collected from growing extension shoots of each of the 3 cultivars. Each of the 6 treatment combinations used 50 larvae. We reared the larvae in an insectary to provide natural fluctuations in temperature and daylength (without direct sunlight). At the same time, a separate test was performed to measure development and survival under constant conditions. We reared 50 larvae on the sixth leaf of "McIntosh" extension shoots in vials in a 16:8 LD growth chamber at $21.1^{\circ} \mathrm{C}$.

Late-season Experiments. Because of the formation of terminal buds, we modified the design of the second set of experiments, which were begun on 10 and 11 July, when very few extension shoots were still growing on "Rome" trees. Although terminal bud set was not as advanced on the other cultivars as it was on "Rome" trees, the rate of bud set was increasing on "McIntosh" and RIG trees over what it had been earlier. Therefore, we compared development and mortality on growing and non-growing tip leaves. Our field observations (Onstad 1985) and those of Chapman and Lienk (1971) indicated that this comparison would represent the 2 main options for the OBLR larva in the summer. The summer larva can develop on tip leaves from a non-growing shoot that had set its terminal bud, or it can start developing on a growing tip and continue feeding, after terminal-bud set, on the non-growing shoot. In fact, beginning on 24 July, we were forced to substitute leaves from non-growing shoots for those from growing shoots on "McIntosh" and RIG trees.

The late-season experiment performed in the insectary had 2 parts. In one test, each group of larvae was reared on the first leaf of a non-growing terminal from 1 of the 3 cultivars. We used 50 larvae in each of the 3 treatments. In the second test, larvae were reared on leaves from either growing or non-growing tips of "McIntosh" or RIG trees. Again, 50 larvae were used in each of the 4 treatment combinations; 2 groups were the same ones evaluated in the first test.

In another late-season experiment, we reared 100 larvae in the growth chamber under the same constant conditions previously described. Half were reared on the first leaf of "McIntosh" non-growing extension shoots and half were reared on the sixth leaf of "McIntosh" shoots. The latter group was fed leaves from growing extension shoots (as in the early-season experiment) until 24 July (day 14), when we switched to non-growing shoots.

In the same growth chamber, we also measured the development and mortality of 2 groups of 30 larvae reared on the second leaf from RIG growing shoots. These observations (one group initiated on $20 \mathrm{July}$, the other on $30 \mathrm{July}$ ) allowed us to verify observations made in the insectary.

Statistical Tests. A variety of statistical tests and procedures were needed to analyze the data collected during these experiments. We used 2 methods for analyzing larval mortality. For larval survivorship curves, we used linear regression (Draper and Smith 1981). To gain a different perspective on mortality, we used the nonparametric rank test of Kruskal and Wallis (1952) to analyze the larval lifetimes, which were not normally distributed. We used analysis of variance to study development times.

Computation of Physiological Time. To calculate physiological time outdoors we obtained daily maximum and minimum temperatures from the local weather station. Phys- 
Table 1. Means and standard deviations of larval development times in degree-days (base $5.25^{\circ} \mathrm{C}$ ) for earlyseason experiment

\begin{tabular}{lccc}
\hline \multirow{2}{*}{$\begin{array}{l}\text { Apple } \\
\text { cultivar }\end{array}$} & \multicolumn{2}{c}{ Leaf type* $^{*}$} & \\
\cline { 2 - 4 } Rome & Young & Old & All \\
& $418.4 \pm 82.3$ & $517.3 \pm 70.5$ & $456.4 \pm 90.1$ \\
McIntosh & $n=8$ & $n=5$ & $n=13$ \\
& $382.8 \pm 58.1$ & $576.5 \pm 45.9$ & $426.8 \pm 99.4$ \\
RIG & $n=17$ & $n=5$ & $n=22$ \\
& $403.5 \pm 60.2$ & $531.1 \pm 94.0$ & $441.0 \pm 91.0$ \\
All & $n=12$ & $n=5$ & $n=17$ \\
& $397.2 \pm 64.3$ & $541.6 \pm 72.3$ & $438.9 \pm 93.4$ \\
& $n=37$ & $n=15$ & $n=52$ \\
\hline
\end{tabular}

*The young and old leaves are the second and sixth leaves on a terminal.

iological time between egg hatch and pupation and between hatch and adult emergence was measured in terms of degree-days (DD) with a base temperature of $5.25^{\circ} \mathrm{C}$. We used degree-days with a $6.0^{\circ} \mathrm{C}$ base to measure pupal development. We calculated the base temperatures in an analysis of other laboratory data (Onstad 1985). In a comparison with temperatures and degree-days recorded in the screened insectary, we found no significant or consistent difference between the 2 locations. Furthermore, we could not demonstrate any significant difference between vial and air temperatures in the insectary using an automatic data-logger.

\section{Results}

(A). Development. 1. Early-season test in the insectary. The larval development times for the 6 treatments of this experiment are presented in Table 1. Larvae reared on young leaves (second from tip) developed more quickly than the other groups. In general, survival to pupation was higher for those that developed quickly. Larvae reared on young leaves had a mean development time of $397 \mathrm{DD}_{5.25}$, whereas those reared on older leaves (sixth from tip) developed in $542 \mathrm{DD}_{5.25}$ on average (Table 1). The development times from hatch to adult emergence were highly correlated with larval development times (Table 2).

The 2-way analysis of variance indicated that leaf type had a significant influence on larval development $(F=46, \mathrm{df}=1$ and $46, P<0.0001)$ and time to adult emergence $(F=31$, $\mathrm{df}=1$ and $28, P<0.0001)$. There was no effect of cultivar in either case; both $F$-values were 1 or less $(P>0.35)$. The cultivar-leaf interactions were also non-significant ( $F$-values $<1.90, P>0.16$ ). In a 3 -way analysis of variance, there were no significant interactions between sex and leaf type or sex and cultivar $(F$-values $<2.40, P>0.11)$, and the results

Table 2. Means and standard deviations of development times from eclosion to ecdysis in degree-days (base $5.25^{\circ} \mathrm{C}$ ) for early-season experiment

\begin{tabular}{lccc}
\hline \multirow{2}{*}{$\begin{array}{l}\text { Apple } \\
\text { cultivar }\end{array}$} & \multicolumn{3}{c}{ Leaf type* } \\
\cline { 2 - 4 } Rome & Young & Old & All \\
\hline \multirow{2}{*}{ McIntosh } & $519.6 \pm 44.2$ & $655.3 \pm 64.3$ & $587.4 \pm 88.4$ \\
& $n=5$ & $n=5$ & $n=10$ \\
RIG & $531.0 \pm 62.8$ & $696.7 \pm 59.2$ & $551.7 \pm 82.8$ \\
& $n=14$ & $n=2$ & $n=16$ \\
All & $524.1 \pm 35.9$ & $614.9 \pm 69.3$ & $558.1 \pm 65.7$ \\
& $n=5$ & $n=3$ & $n=8$ \\
& $527.2 \pm 53.0$ & $651.4 \pm 64.9$ & $563.7 \pm 80.1$ \\
& $n=24$ & $n=10$ & $n=34$ \\
\hline
\end{tabular}

*The young and old leaves are the second and sixth leaves on a terminal. 


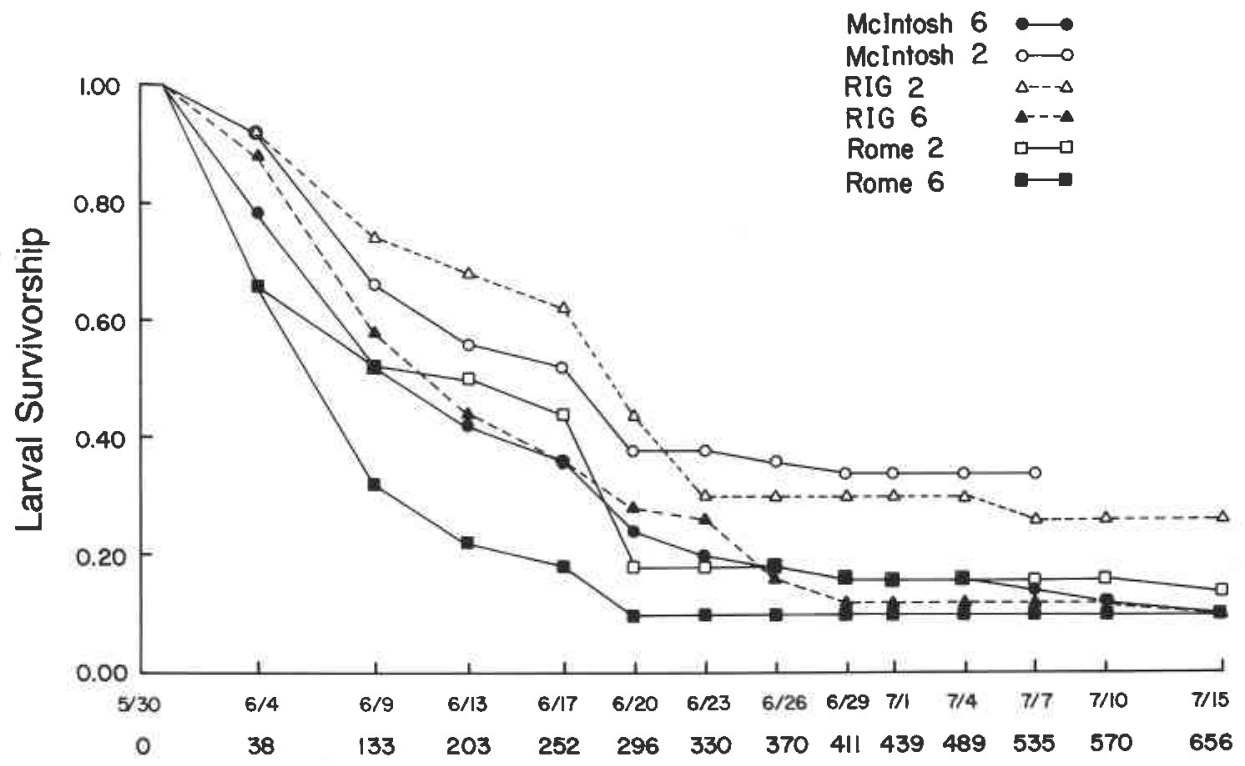

Date and Degree-Days (base $5.25^{\circ} \mathrm{C}$ ) from Hatch

FIG. 1. Survivorship of obliquebanded leafroller larvae as a function of time. Larvae were fed leaves from 3 apple cultivars and from 2 positions relative to branch tips (i.e. second and sixth).

of the 2-way analysis were confirmed. In general, male larvae developed faster than female larvae.

The mean development time for all 55 larvae reared in the insectary and the growth chamber was $444 \mathrm{DD}_{5.25}(\mathrm{SD}=95$, range $=318-618)$. Development of all 37 pupae in both early-season tests had a mean time of $140 \mathrm{DD}_{6.0}(\mathrm{SD}=13)$.

2. Other experiments. In the early-season laboratory test, the 3 larvae that survived to pupation had a mean development time of $528 \mathrm{DD}_{5.25}$ and none of these died during the pupal stage. In the late-season laboratory test, however, the mean for the 3 larvae was $655 \mathrm{DD}_{5.25}$, and all of these died in the pupal stage.

Eight larvae that were reared in the insectary survived to pupation in the late-season experiment, but half of these died before emergence. The larvae developed in a mean time of $562 \mathrm{DD}_{5,25}(\mathrm{SD}=74)$. The 2 larvae reared on RIG growing-tip leaves each developed in $489 \mathrm{DD}_{5.25}$, while the mean for the 6 reared only on non-growing tip leaves was $587 \mathrm{DD}_{5,25}(\mathrm{SD}=70)$.

(B) Survival. In the analysis of larval survivorship (Figs. 1 and 2), we used linear regression with dummy or indicator variables (Draper and Smith 1981). These are zero-one variables that indicate when a factor is included in an equation. For example, we used dummy variables for the "Rome" and RIG treatments; "McIntosh" was the standard, which is automatically accounted for in an equation. In all of the final models, the residual errors were normally distributed.

1. Early-season test in the insectary. The clear difference in Fig. 1 between the set of survivorship curves with open symbols (young leaves) and the set with closed symbols (old leaves) indicates that larvae survive better on young leaves. The best fit to the data $(n=82)$ was obtained with the following exponential decay model:

$\ln (y)=-0.250-0.00174 \mathrm{DD}-0.00157(\mathrm{DD} \times \mathrm{L6})-0.00113$ (DDxRome) -0.000235 (DD $\times \mathrm{RIG})$

where $y$ is survivorship (proportion), DD is degree-days (base $5.25^{\circ} \mathrm{C}$ ), and $\mathrm{L6}$ is the 


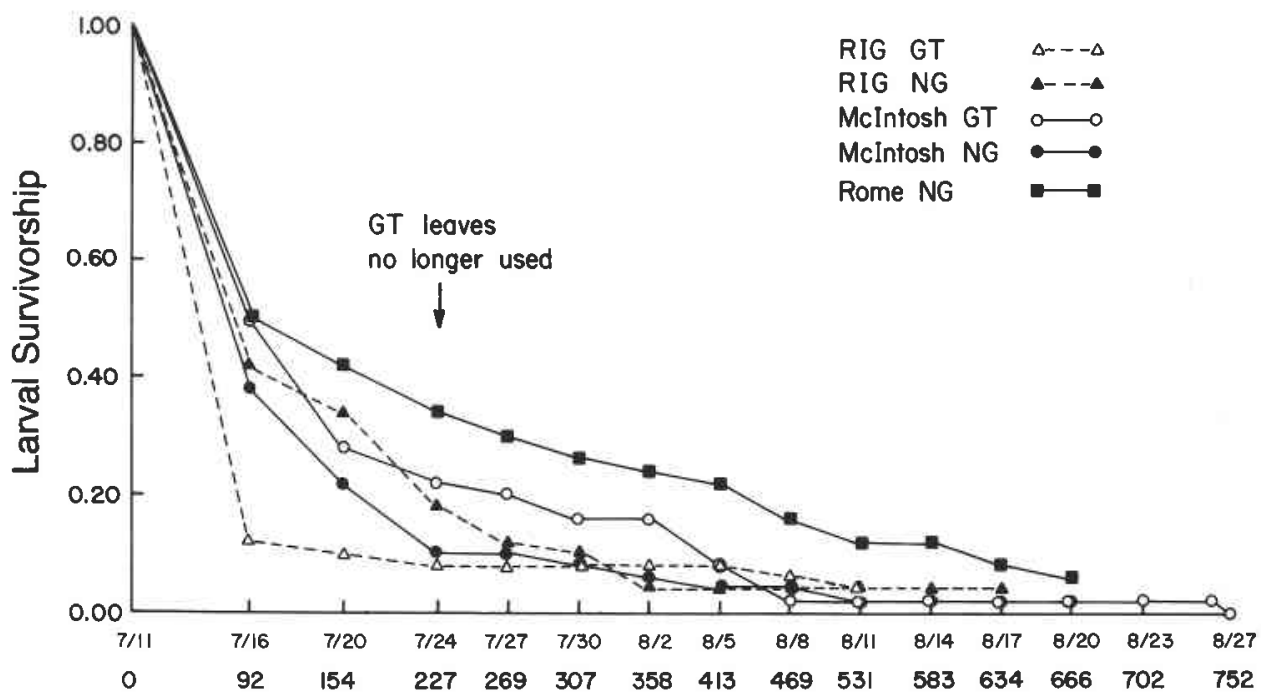

Date and Degree-Days (base $5.25^{\circ} \mathrm{C}$ ) from July 11

FIG. 2. Survivorship of obliquebanded leafroller larvae as a function of time. Larvae were fed leaves from 3 apple cultivars and from 2 types of branch tips: growing (GT) and non-growing (NG). After 24 July, only leaves from non-growing tips were used.

dummy variable for the old or sixth leaf. The $t$-statistics for the coefficients in order of appearance are as follows: $-4.31,-8.85,-10.69,-6.29,-1.31$. Larvae reared on old leaves and those reared on leaves from "Rome" trees had lower survival than those reared on "McIntosh" and young leaves (Fig. 1). The influence of RIG ( $t=-1.31)$ is questionable. In a comparison of predicted and observed $y$ values, this exponential model accounted for $93 \%$ of the variability. Regressions with other sets of variables indicated that there was no significant interaction between cultivar and leaf type.

2. Late-season test in the insectary. Survivorship of larvae reared on non-growing tip leaves from "Rome" trees was higher than it was for those reared in the 4 other treatments (Fig. 2). Because the design did not include a "Rome"' growing-tip treatment, we performed 2 statistical analyses. For the case in which larvae were reared on leaves from the tips of non-growing terminals of all 3 cultivars, the best exponential decay model is:

$\ln (y)=-0.465-0.00590 \mathrm{DD}+0.00286(\mathrm{DD} \times \mathrm{Rome})+0.000804(\mathrm{DD} \times \mathrm{RIG})$

where $y$ is survivorship (proportion) and DD is degree-days (base $5.25^{\circ} \mathrm{C}$ ). The $t$-statistics for the coefficients in order of appearance are as follows: $-4.14,-17.93,8.83$, and 2.48. With $n=38$, all coefficients are significantly different from zero. In a comparison of predicted and observed $y$ values, the exponential model accounted for $94 \%$ of the variability. Equation 2 indicates that larvae reared on both RIG and "Rome" had significantly higher survival rates than larvae on "McIntosh".

In the second test, larvae were reared on leaves from either growing or non-growing tips of "McIntosh" or RIG trees. In this case, we used the growing-tip leaf treatment as the second standard. The best equation for this data set $(n=51)$ was the simplest exponential decay model without dummy variables $(\ln (y)=-0.648-0.005 \mathrm{DD})$. This function of degree-days explained $86 \%$ of the variability. The $t$-statistics for the DD $\times$ RIG, $\mathrm{DD} \times$ Non-growing tip, and the interaction variables were all within 1 unit of zero. Therefore, unlike Eq. 2, this analysis did not indicate a significant difference between 


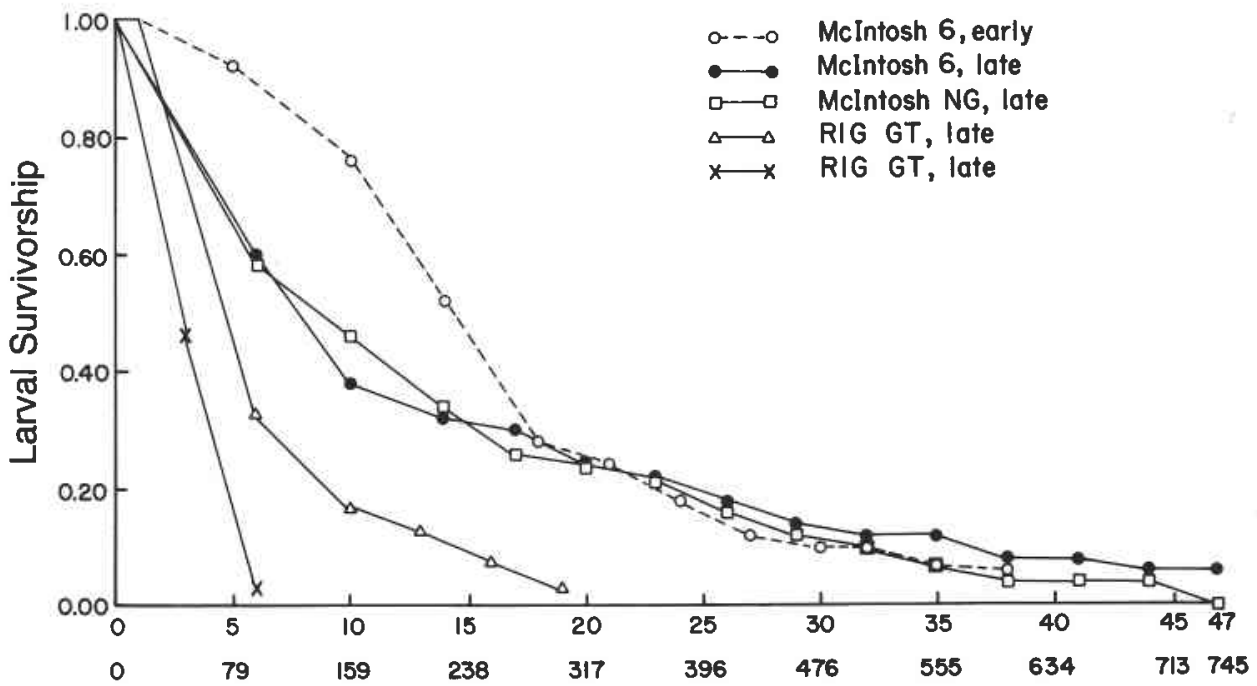

Days and Degree-Days (base $5.25^{\circ} \mathrm{C}$ ) from Hatch

FIG. 3. Survivorship of obliquebanded leafroller larvae as a function of time in a growth chamber. During the early part of the season, larvae were fed leaves sixth from the tip of "McIntosh". Later in the season, larvae were fed the sixth leaves from growing and non-growing terminals or tip leaves from non-growing (NG) terminals on "McIntosh". Two groups were reared on growing-tip (GT) leaves from "R.I. Greening".

"McIntosh" and RIG. This lack of difference can also be seen in Fig. 2 where all 4 lower curves overlap.

3. Additional analysis of insectary experiments. We used the Kruskal-Wallis test to compare the distributions of larval lifetimes for the treatments in both insectary experiments. It is a rank test that produces a single-parameter statistic, $H$, which is distributed approximately as chi-square. In the following analyses, the results are slightly conservative (and less likely to indicate a difference) because we made no corrections for ties in lifetimes. For survivors to pupation, lifetimes were set at 700 and $800 \mathrm{DD}_{5.25}$ in the earlyand late-season experiments, respectively.

Both cultivar $(H=17, n=300, \mathrm{df}=2, P<0.005)$ and leaf type $(H=12.6, n=300$, $\mathrm{df}=1, P<0.005$ ) influenced the distributions of larval lifetimes in the early-season experiment. These results support those of the regression analysis (Eq. 1). For the first part of the late-season experiment involving all 3 cultivars and non-growing terminals, there were no differences between the distributions of lifetimes for larvae reared on each of the cultivars $(H=3.6, n=150, \mathrm{df}=2, P<0.40)$. This does not support the result of the regression analysis (Eq. 2).

4. Experiments in the growth chamber. During the early stages (first 14 days), the survival rate was clearly lower for the larvae reared on "McIntosh" leaves later in the season than for those in the earlier test (Fig. 3). However, as Fig. 3 clearly shows, there was no difference in the survival of larvae reared on either the sixth leaf or the tip leaf of "McIntosh" terminals collected late in the season. The bottom 2 curves in Fig. 3 correspond to the curve for the RIG growing-tip treatment in Fig. 2. All 3 indicate that mortality was very high for small larvae reared on RIG growing-tip leaves late in the season.

5. Seasonal influence on mortality in the insectary. We compared the survivorship for larvae reared on young leaves (growing tip) collected from "McIntosh" and RIG trees (Fig. 4). Clearly, survival was higher for larvae reared on leaves early in the season. Because only 4 observations were made in the late-season experiment before growing tips 


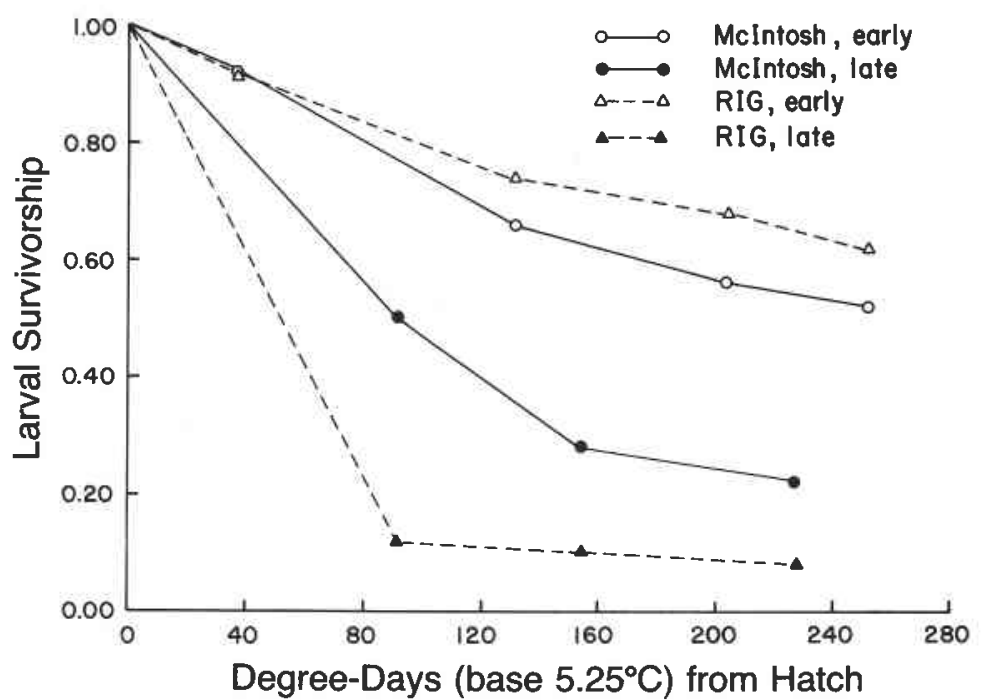

FIG. 4. Survivorship as a function of physiological time for part of the larval stage of the obliquebanded leafroller. During 2 parts of the season, larvae were fed leaves (second) from the growing tip on branches of 2 apple cultivars.

were no longer available, we were forced to use fewer points from the curves of the 2 experiments than are presented in Figs. 1 and 2. Thus, we used the first 4 observations of the late-season test and the first 5 of the early-season test to create Fig. $4(n=18)$. Because the weather during the 2 experimental periods was similar and the predictor is degreedays, it is likely that seasonal changes in the trees' chemical and physical constitutions increased mortality later in the season.

\section{Discussion}

Development and mortality of OBLR were similar on all 3 apple cultivars. Only in the early-season experiment did a cultivar ("Rome") significantly affect (decrease) survival (Fig. 1). In all other cases, there were no consistent patterns indicating a significant effect of cultivar. Fluckiger and Benz (1982) also did not observe a significant difference in the larval development of Adoxophyes orana on 2 apple cultivars.

Larvae reared on young leaves had faster developmental rates and higher survival rates than those reared on old leaves. The same was true for the resulting pupae. Raupp and Denno (1983) concluded in their review that mortality is greater and development slower for herbivorous larvae reared on old leaves. Dumbleton (1939) observed slower larval development by a tortricid leafroller on mature apple leaves. In our early-season experiment (Table 1), mean larval development on young leaves was $397 \mathrm{DD}_{5.25}$ and development on old (sixth) leaves was $542 \mathrm{DD}_{5.25}$. With an average of $14 \mathrm{DD}_{5.25}$ per day in western New York in the summer, this difference of approximately 10 days in the development times makes knowledge of the insect's distribution and behavior within the hostplant's canopy important for phenological forecasting and management. Furthermore, differences in mortality and development are likely to be greater for larvae on leaves below the sixth leaf on the branch (i.e. older than $300 \mathrm{DD}_{5,25}$ ).

Larvae reared on a given cultivar and a given type of leaf early in the season tended to have faster developmental rates and higher survival rates than those reared on the same leaves and cultivar later in the season. Figure 4 clearly shows that larval mortality was higher later in the season. Figure 3 also shows a difference in survivorship for larvae reared on sixth leaves early in the season (all pupae survived) and those reared on similar leaves 
later in the season (all of the pupae died). In addition, the mean development times for the same larvae, which were reared under constant conditions in a growth chamber, were $528 \mathrm{DD}_{5.25}$ early in the season and $655 \mathrm{DD}_{5.25}$ later on.

Our results concerning the influence of tree phenology are similar to the observations made by Hough and Pimentel (1978), who found that gypsy-moth larval mortality was lower and development faster in May than in June. In addition, our results support and expand the "favorable food factor" hypothesis of Chapman et al. (1968). They postulated that the density of OBLR is lower in the summer generation than it is in the spring generation because of the lack of young succulent foliage. Our results indicate that tree maturation might play an important role by reducing the quality of young foliage as the season progresses. Nitrogen content and water content tended to decline and the specific leaf weight tended to increase in the apple leaves during the season (Onstad 1985). Scriber and Slansky (1981) have described how similar phenological changes in leaves were correlated with similar effects on a variety of insects.

Scriber and Slansky (1981) and Hough and Pimentel (1978) discussed the importance of studying the whole larval (and pupal) stage in experiments concerning nutritional ecology. Both reports stated that the youngest larvae are likely to be the most sensitive to differences in the quality of food sources. Our survivorship curves demonstrated that this is true; most deaths occurred in the early larval stadia. In their study of tussock-moth larvae, Mason and Baxter (1970) observed that new foliage was the preferred food for young larvae and that lack of preferred food caused significant starvation among early instars even when other foliage was present.

Caution must be used, however, in relating the results obtained under the artificial conditions of our experiments (excised leaves in vials) to conditions in apple orchards. For example, in the early-season experiments, the rates of survival to pupation were $18 \%$ in the insectary and $6 \%$ in the growth chamber. The same values for the late-season experiments were both $3 \%$. Even for larvae reared on young leaves in the insectary early in the season the survival rate was only $25 \%$. Nevertheless, other laboratory and field data (Onstad 1985 ) indicate that survival rates between $10 \%$ and $50 \%$ can be expected for OBLR larvae on apple.

After they reared OBLR larvae on an artificial diet, Gangavalli and AliNiazee (1985) determined that the mean development time for the larval stage was $435 \mathrm{DD}$ (base $10.8^{\circ} \mathrm{C}$ ). In our study, larvae reared on old leaves in the growth chamber late in the season required $426 \mathrm{DD}_{10.8}$ for development. However, under the same conditions earlier in the season, mean development time was only $343 \mathrm{DD}_{10.8}$. Because development time is even shorter on younger apple leaves, especially for earlier periods, diet seems to be crucial in determining the correct rates of development.

The average developmental rates for the larval and pupal populations will be determined by the behavior and spatial distributions of OBLR larvae in apple tree canopies. If most surviving larvae feed only upon branch tips, then development might be faster than if larvae also feed upon older leaves. Development and mortality are also affected by tree maturation during the season. Furthermore, additional information will be needed to determine how weather (e.g. cold spells, droughts) and fertilizer use (Scriber 1984) affect the OBLR populations either directly or indirectly through their effects on tree phenology and leaf quality. Given this complexity, it may be difficult to predict precisely phenological events for OBLR populations in apple orchards.

\section{Acknowledgments}

We thank Malcolm Bourne, Stanley Comstock, Alan Lakso, Robert Seem, and Roger Way for their help. We also thank Paul Chapman and Sieg Lienk for their thoughtful criticisms of this paper. This paper was part of David Onstad's Ph.D. dissertation submitted to Cornell University. 


\section{References}

Chapman, P.J., and S.E. Lienk. 1971. Tortricid fauna of apple in New York. N.Y. State Agric. Expt. Stn., Geneva, N.Y. Spec. Publ. 122 pp.

Chapman, P.J., S.E. Lienk, and R.W. Dean. 1968. Bionomics of Choristoneura rosaceana. Ann. ent. Soc. Am. 61: 285-290.

Draper, N.R., and H. Smith. 1981. Applied regression analysis, 2nd ed. John Wiley and Sons, New York. 709 pp.

Dumbleton, L.J. 1939. Contribution to the physical ecology of Tortrix postvittana, Walk. (Lep.). Bull. Ent. Res. 39: 309-319.

Fluckiger, C.R., and G. Benz. 1982. A temperature-driven model to simulate the population development of the summerfruit tortrix, Adoxophyes orana. Ent. Expt. Appl. 32: 161-172.

Gangavalli, R.R., and M.T. AliNiazee. 1985. Temperature requirements for development of the obliquebanded leafroller, Choristoneura rosaceana (Lepidoptera: Tortricidae). Environ. Ent. 14: 17-19.

Hough, J.A., and D. Pimentel. 1978. Influence of host foliage on development, survival, and fecundity of the gypsy moth. Environ. Ent. 7: 97-102.

Kruskal, W.H., and W.A. Wallis. 1952. Use of ranks in one-criterion analysis of variance. J. Am. Stat. Assoc. 47: 583-621.

Mason, R.R., and J.W. Baxter. 1970. Food preference in a natural population of the Douglas-fir tussock moth. J. econ. Ent. 63: 1257-1259.

Onstad, D.W. 1985. Options for design and control in the management of a tortricid leafroller (Choristoneura rosaceana) in apple orchards. Ph.D. thesis, Cornell University, Ithaca, N.Y.

Raupp, M.J., and R.F. Denno. 1983. Leaf age as a predictor of herbivore distribution and abundance. pp. 91124 in Denno, R.F., and M.S. McClure (Eds.), Variable Plants and Herbivores in Natural and Managed Systems. Academic Press, New York. 717 pp.

Reissig, W.H. 1978. Biology and control of the obliquebanded leafroller on apples. J. econ. Ent. 71: 804809.

Scriber, J.M. 1977. Limiting effect of low leaf-water content on the nitrogen utilization, energy budget, and larval growth of Hyalophora cecropia (Lepidoptera: Satumiidae). Oecologia 28: 269-287.

- 1984. Host-plant suitability. pp. 159-204 in Bell, W.J., and R.T. Carde (Eds.), Chemical Ecology of Insects. Chapman and Hall, London. 524 pp.

Scriber, J.M. , and F. Slansky, Jr. 1981. The nutritional ecology of immature insects. Annu. Rev. Ent. 26: 183211.

(Date received: 198504 15; date revision received: 19851001 ; date accepted: 19851109 ) 